Utah State University

DigitalCommons@USU

$10-29-2013$

\title{
STORM: Sounding and Tracking Observatory for Regional \\ Meteorology to Launch in 2016
}

Gail Bingham

Utah State University

Follow this and additional works at: https://digitalcommons.usu.edu/sdl_pubs

\section{Recommended Citation}

Bingham, Gail, "STORM: Sounding and Tracking Observatory for Regional Meteorology to Launch in 2016" (2013). Space Dynamics Lab Publications. Paper 158.

https://digitalcommons.usu.edu/sdl_pubs/158

This Article is brought to you for free and open access by the Space Dynamics Lab at DigitalCommons@USU. It has been accepted for inclusion in Space Dynamics Lab Publications by an authorized administrator of DigitalCommons@USU. For more information, please contact digitalcommons@usu.edu.

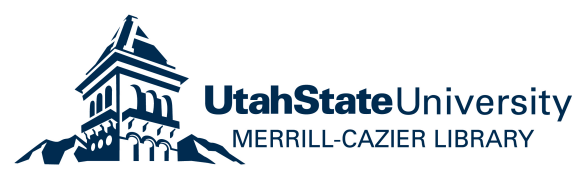




\title{
STORM $_{\mathrm{TM}}$ - sounding and tracking observatory for regional meteorology to launch in 2016
}

Gail Bingham*a, Scott Jensen ${ }^{\mathrm{b}}$, John Elwell ${ }^{\mathrm{b}}$, Joel Cardon ${ }^{\mathrm{b}}$, David Crain ${ }^{\mathrm{c}}$, Hung-Lung (Allen) Huang ${ }^{d}$, William L. Smith ${ }^{d}$, Hank E. Revercomb ${ }^{\mathrm{e}}$, Ron Huppif

${ }^{a}$ Space Dynamics Laboratory, 1695 N. Research Park Way, N. Logan, UT; $84341^{\mathrm{b}}$ Advanced Weather Systems Foundation, Utah State University, 570 N. Research Park Way, N. Logan, UT; 84341, 'GeoMetWatch, 1770 Research Park, N. Logan, UT, 84341; d University of Wisconsin, 1225 W. Dayton St., Madison, WI, 53706 and Hampton University, 100 E. Queen St., Hampton VA, 23668, and 'SSEC, University of Wisconsin, 1225 W. Dayton St., Madison, WI, 53706, ${ }^{f}$ Ron Huppie, 6 Fairlane Terrace Winchester, MA 01890

\begin{abstract}
Ultra-spectral sounders (USS) in low earth orbit have significantly improved weather forecast accuracy in recent years, and their impact could be significantly improved with reduced revisit times. The GeoMetWatch, Inc. ${ }^{1}$ Sounding and Tracking Observatory for Regional Meteorology (sтовмтм) program is designed to place a constellation of six USS units in spaced geostationary (GEO) positions around the earth. From GEO, the repeat time for a specific weather feature can be reduced to minutes, and the vertical temperature, water vapor and wind profiles can provide detailed warnings not available by any other means.

The STORM $\mathrm{TM}_{\mathrm{TM}}$ sensor, a derivative of the Geosynchronous Imaging Fourier Transform Spectrometer (GIFTS) EDU that was designed and built for NASA by Utah State University (USU) and rigorously tested in 2006, will be launched on a commercial geostationary satellite in late 2016. It combines advanced technologies to provide improved performance and reliability over the original EDU. From GEO the USS can observe surface thermal properties and atmospheric weather and chemistry variables in four dimensions. This paper provides an overview of the $\mathrm{STORM}_{\mathrm{TM}}$ instrument and the measurement concept. STORM $_{\mathrm{TM}}$ 's USS will provide data of the same quality as the current LEO satellite sounders (AIRS, CrIS, and IASI) but with the ability to track storm development with soundings and images at any desired rate. Wind profiles obtained from a time sequence of $\mathrm{STORM}_{\mathrm{TM}}$ water vapor retrieval images will provide additional input to now casting and regional models.
\end{abstract}

Keywords: Atmospheric sounding, geostationary, ultra-spectral sounder, GIFTS, STORM $\mathrm{TM}_{\mathrm{TM}}$, severe weather, commercial satellite hosting

\section{INTRODUCTION}

Ultra-spectral sounders (USS) in low earth orbit have significantly improved weather forecast accuracy in recent years, and their impact could be significantly improved with reduced revisit times. The impact of the first generation LEO ultra-spectral sounders (USS), the Atmospheric Infrared Sounder (AIRS) on NASA's Aqua spacecraft, the Infrared Atmospheric Sounding Interferometer (IASI) on EUMETSAT's METOP-A $\&$ B and the Crosstrack Infrared Sounder (CrIS) on the NOAA JPSS S-NPP satellite have had a major impact on the accuracy of the world's major forecast center products ${ }^{2}$. The rich spectral structure in the infrared region of the atmosphere was known to provide information on the vertical profiles of water vapor and temperature and atmospheric sounding capability from space was first demonstrated by the NASA Nimbus 3 satellite launched on April 13, 1969. Nimbus 3 carried both an Infrared Interferometer Spectrometer (IRIS) to measure atmospheric temperature, water vapor, and ozone in the vertical and a Satellite Infrared Spectrophotometer (SIRS) to provide similar temperature readings. Both the grating and interferometer instruments returned measurements of the IR spectra (See Figure 1) that allowed the beginning of observational sounder development ${ }^{3}$.

*Gail.Bingham@sdl.usu.edu; phone 1435 757-2931; fax 1435 713-3430; www.spacedynamics.org

Infrared Remote Sensing and Instrumentation XXI, edited by Marija Strojnik Scholl, Gonzalo Páez, Proc. of SPIE Vol. 8867, 88670X · @ 2013 SPIE · CCC code: 0277-786X/13/\$18 · doi: 10.1117/12.2030601 


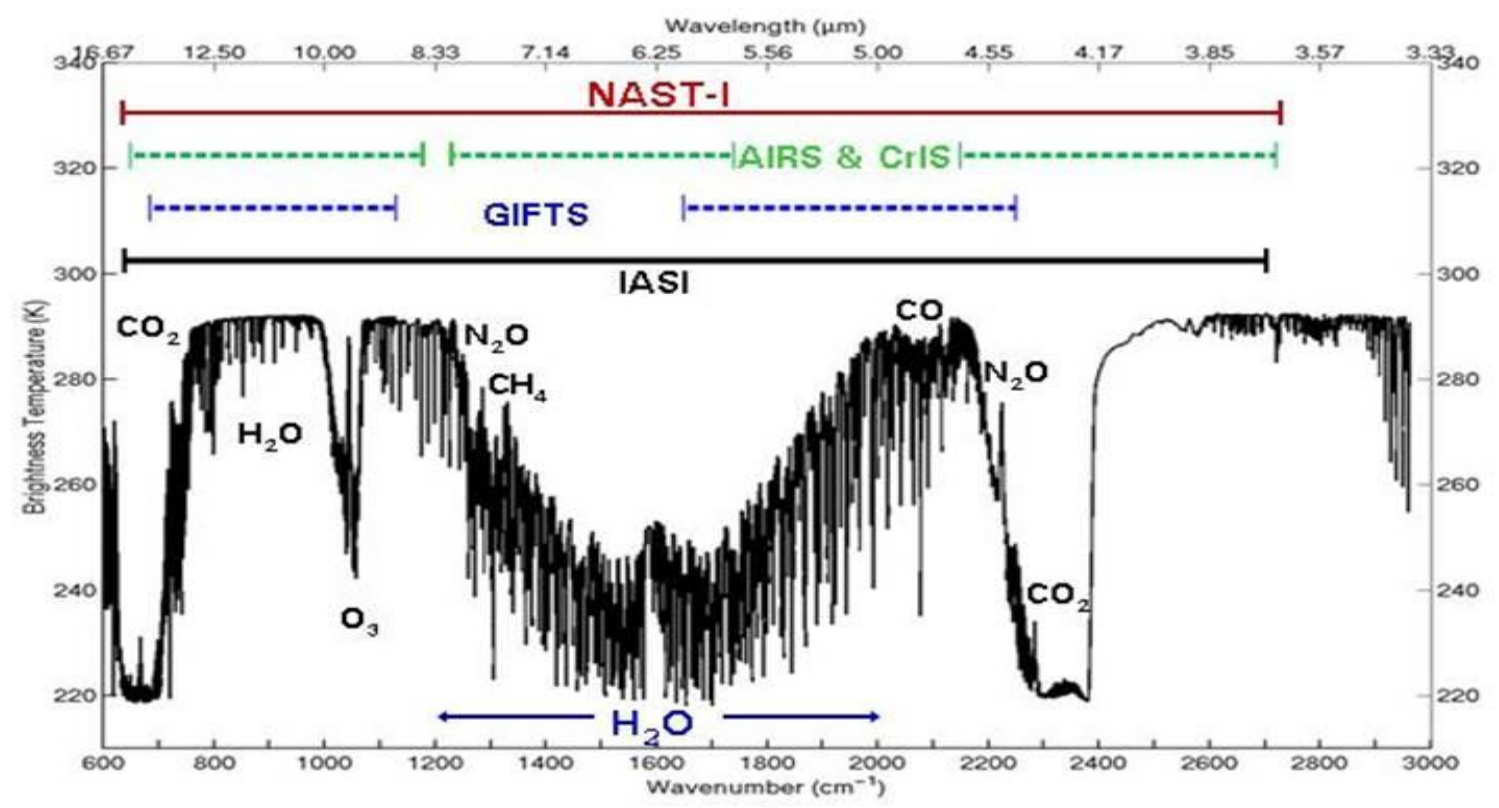

Figure 1. The IR spectra used for atmospheric sounding of the atmosphere and the regions used by some of the current ultra-spectral sounders.

The LEO constellations are spaced to provide the global atmospheric state observations needed to initialize global numerical weather models. They provide excellent coverage for relatively slow moving features. However, for severe weather nowcasting, these data are limited by the spaced crossing times of these valuable assets. To provide rapid updates on storm development, the weather services rely on Geostationary (GEO) observatories. By orbiting over a fixed earth location, they provide the cloud motion pictures that millions observe and interpret during their evening news programs. The imaging and multispectral sounding capability from GEO has evolved significantly since the first weather satellite in that orbit, NASA's Geostationary Applications Technology Satellite demonstrated the ability to see weather systems in motion after its launch in December 1966. The first step toward operational capability was Synchronous Meteorological Satellite (SMS-A), launched in May 1974. SMS-1 (the letter being changed to a number after launch), was a spin-stabilized satellite whose principle instrument was the Visible Infrared Spin Scan Radiometer (VISSR) which provided both day and night imagery of the Earth's surface and cloud cover. The NASA SMS series $(1 \& 2)$ were followed by "operational" satellites in the Geostationary Operational Environmental Satellite (GOES) series, beginning with GOES-1 in October 1976. By adding more channels to the VISSR instrument, the VISSR Atmospheric Sounder (VAS) was included in GOES-4, but with limited capability as it had to share access with the imaging system. However the VAS provided the research base $\mathrm{s}^{4}$ for the later development of a dedicated sounder on the GOES I-M series spacecraft. GOES 8, launched in 1994, provided the first GOES sounder data stream, and being located on a three axis stabilized spacecraft, could now stare at a location to develop the signal to noise required for more accurate measurements.

The GOES-8 series sounders were multi-spectral radiometers (18 channels) that observed the radiance with a spectral resolving power (v/dv) of about 100, and therefore had limited vertical resolution (Figure 2). The ultra-spectral sounding requirement developed from the need to obtain higher vertical resolution soundings from the GOES spacecraft to support the production of data that was consistent with the higher horizontal and temporal observations being provided by the imaging system in support of local severe weather forecasting. The first demonstration of this capability came in the form of a series of aircraft instruments. The UW SSEC High-resolution Infrared Sounder (HIS) ${ }^{5}$ first flew on the NASA ER-2 in 1985. An improved (horizontal scanning HIS (S-HIS) and the NPOESS Atmospheric Sounder TestbedInterferometer (NAST-I) ${ }^{6}$ have continued to show that collection of ultra-spectral data from a moving platform is not only feasible, but have been used to validate the first generation of space borne ultraspectral sounders. The Atmospheric Infrared Sounder on NASA's Aqua was the experimental space demonstration of the technique and capability, while the first operational polar orbiting satellite implementation was initiated on the European MetOp-A satellite. The first NOAA ultra-spectral sounder, 
the Crosstrack Infrared Sounder (CrIS), was launched in 2011 on the Suomi-National Polar Partnership (SNPP) satellite. These sensors provide spectral resolutions from 1000 to 10,000 , respectively, providing the additional weighting functions necessary to resolve vertical temperature and water vapor in the 1-2 Km range. High spatial and temporal resolution profiles of water vapor data allow the development of wind profiles that provide another aspect of atmospheric dynamics that are limited in today's databases. With layered wind data, atmospheric chemistry fluxes can be obtained and aircraft routing data more accurate.
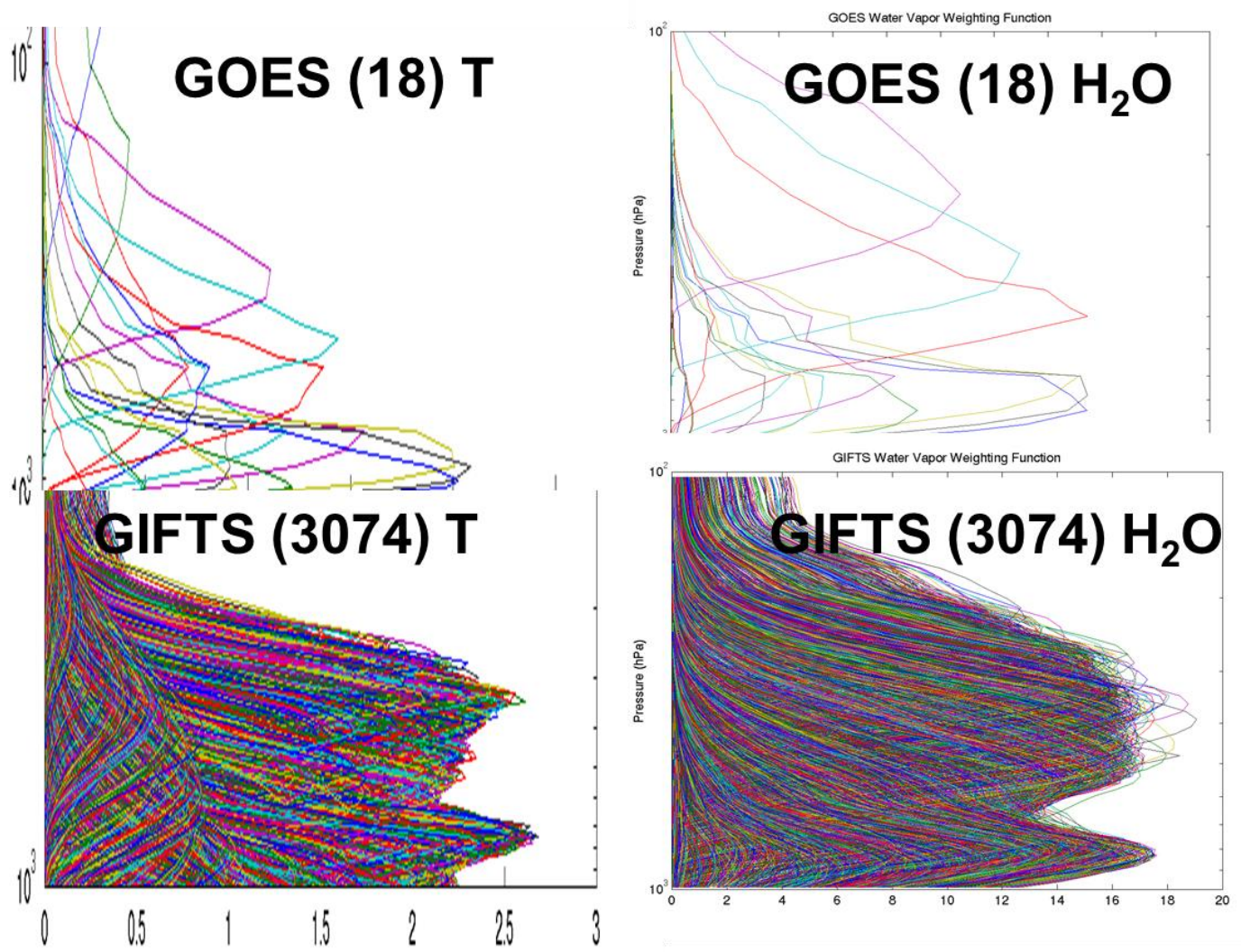

Figure 2. The weighting functions (resolution elements) available for extracting atmospheric profile information for temperature and water vapor from the 18 channel GOES 8 sounder compared with the ultra-spectral capability of a GIFTS-style sensor. Ultra-spectral soundings also benefit from the much greater signal to noise ratio resulting from the nearly redundant extra channel information.

\section{GEOSTATIONARY ULTRA-SPECTRAL SOUNDER DEVELOPMENT}

\subsection{The recognized need}

In the mid-90's NASA decided that they needed to extend some of their development effort to include sensors in geostationary orbit. From the multiple proposals submitted to the call for the next New Millennium Earth Observing program, the Geostationary Imaging Fourier Transform Spectrometer (GIFTS) was selected. The objective of the Earth Observing 3 (EO3) GIFTS ${ }^{7}$ project was to develop and test the new technologies required to move ultra-spectral sounding from LEO to GEO. The EO3 program identified eight technologies to be matured under the GIFTS program. These included the following:

- A cryogenic Michelson interferometer with a spatial sampling system optimized for imaging

- Large area detector arrays and readouts and associated miniaturized cryocoolers

- High speed, ultra-low-power signal processing

- A radiation-hardened vector processor for onboard real-time signal processing and data compression

- Autonomous pointing and control systems for precise image stabilization and feature tracking

- Radiation protection and ultra-low-power electronics

- Lightweight optics and structures to minimize instrument mass

These technologies would not only benefit the EO3 missions, but also other sensors proposed for earth observation. 


\subsection{The GIFTS program}

While originally proposed as a gimbaled, secondary payload on the on NASA's TDRS J satellite, it quickly became obvious that the two programs had serious incompatibilities. By the end of the Phase A study, a new program organization had been developed that involved a dedicated mission support by the US Navy, NOAA and NASA, with the Navy providing both the spacecraft and a launch using the Air Force Space Test Program. Three major challenges faced the GIFTS - IOMI (Indian Ocean METOC Imager) mission, the first being the coordination of objectives and budgets for three agencies. The next two; weight and processing power, were technological and were overcome.

\subsection{GIFTS optical system}

Transferring the ultra-spectral technology from LEO to GEO requires two things, a significantly larger data collection system, and increased on-board processing and communications capabilities. A schematic of the GIFTS optical system is shown in Figure 3. The two-axis pointing mirror has the ability to stop and stare +/- 10 degrees with respect to Earth center, allowing it to view the whole Earth and surrounding space. Viewing surrounding space allows for deep space calibration of the entire optical system and star viewing for navigation verification. A flip in mirror, between M2 and M3, provides sun protection to the following optics and focal planes and provides the capability to view two precision blackbody cavities (provided by UW SSEC. A dichroic after M3 splits off the shorter wavelengths not used by the FTS system and routes the energy to a visible/near IR camera. A filter wheel system can be inserted at this point to allow multispectral imaging, but only a single band was developed for the GIFTS sensor. Six temperature zones were used in GIFTS to provide stable calibration over the full 360 sun exposure experienced daily by a sensor in GEO orbit. The front telescope is passively radiatively cooled, while the later stages use dedicated radiators connected to that stage by loop heat pipes.

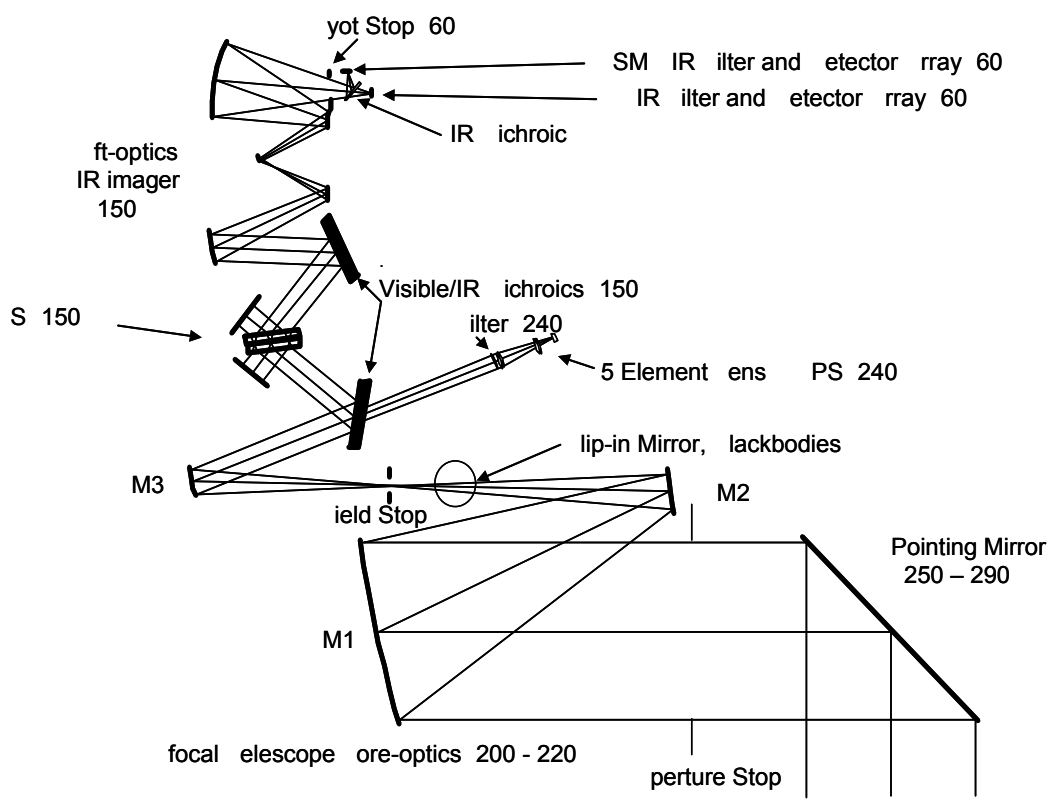

Figure 3. The optical concept of the GIFTS ultra-spectral sounder.

The interferometer cavity and the dichroic are stabilized at $150 \mathrm{~K}$ to minimize self-emission loading on the focal planes and reduces variation in system emission during the diurnal cycle. The compact aft optical system is also controlled at $150 \mathrm{~K}$. The focal plane housing is actively cooled to $60 \mathrm{~K}$ and contains the beam splitter that separates the two measurement bands (see Figure 1). GIFTS was designed for a spacecraft that could execute a yaw flip every 6 months to assure that the passive radiators that controlled optical temperature were always facing away from the sun (see Figure 4). 


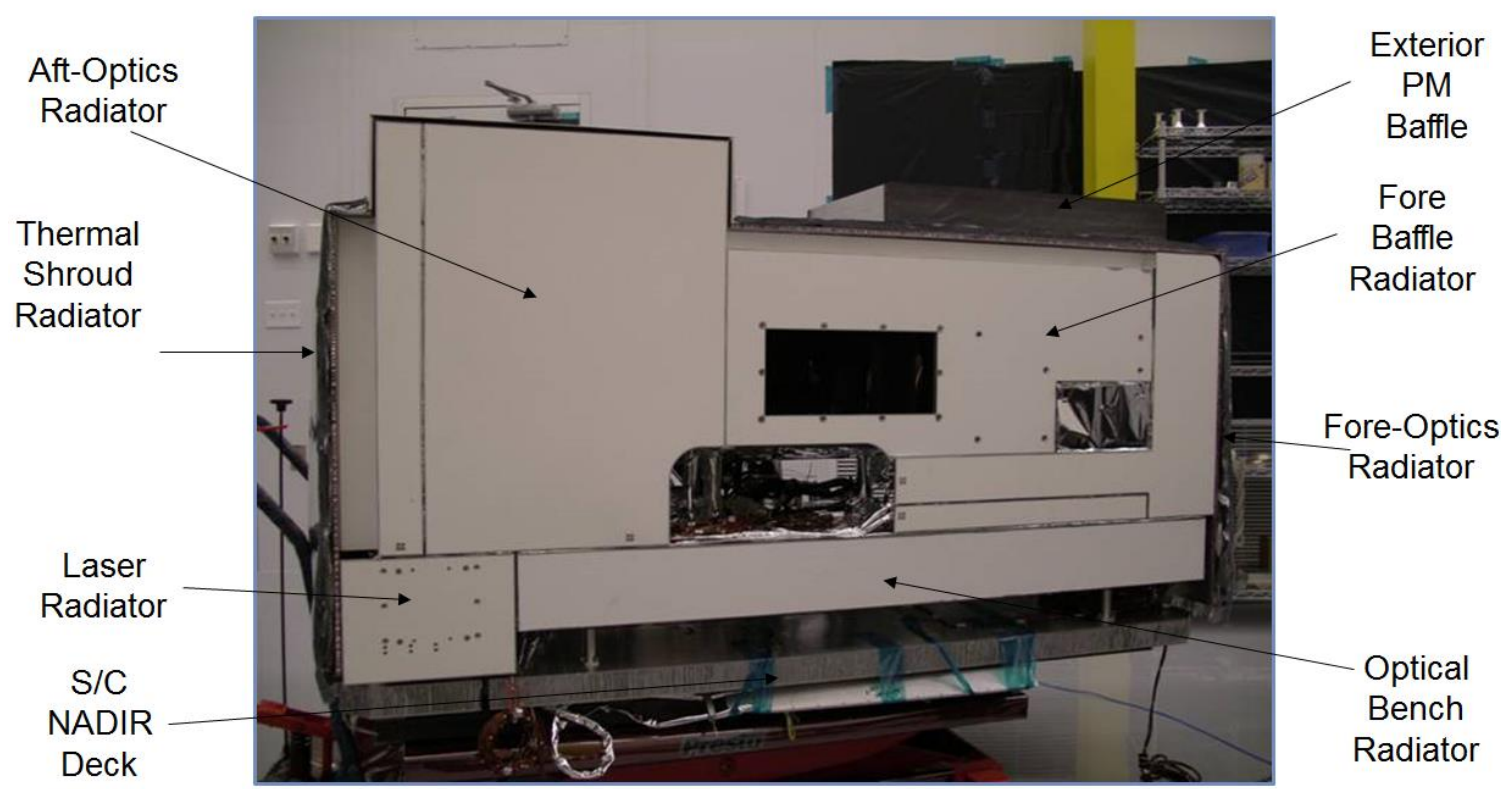

Figure 4. The radiator panels on the anti-sun side of the GIFTS sensor.

\subsection{Focal planes and electronics}

GIFTS is a massively parallel FTS system which incorporates two IR $128 \times 128$ pixel focal planes. Large area format Focal Plane detector Arrays (LFPAs) provide near instantaneous large area coverage with high horizontal resolution. The imaging FTS enables atmospheric radiance spectra to be observed simultaneously for all LFPA detector pixels, thereby providing high vertical resolution temperature and moisture sounding information. Each pixel has an 112ur (4 Km IFOV), giving the GIFTS instrument a square $512 \mathrm{Km}$ field of view at nadir. The full $0.8 \mathrm{~cm}$ interferometer mirror scan requires just less than 11 seconds. Since each pixel images a different spot on the Earth, the instrument collects 16,384 separate interferograms (actually 32768 when both FPAs are considered) in that period. Even when the time required to step the mirror to an adjacent location is considered, GIFTS could collect more than 80,000 atmospheric sounding per minute. With its rapid repeat capability, a GEO ultra-spectral sounder can provide a 4D image of the atmosphere, the fourth dimension (time, being provided by the geosynchronous satellite platform), which enables near continuous imaging of the atmosphere's three-dimensional structure. The state of the art for LFPAs in the year 2000 required significant additional development and the GIFTS units were not perfect. This is an area of significant progress in the last decade, and the STORM $\mathrm{TM}_{\mathrm{TM}}$ FPA vendor will not suffer the significant learning curve faced by the GIFTS vendor.

The second significant challenge in the GIFTS design was the data collection and processing system. The design of the data collection and processing system is shown in

Figure 5. The LFPAs had 20 high-speed analog data outputs that were digitized at 14 bits and co-added to 16 bit resolution. The 32,384 interferograms (113 Mpixels/sec) were fed to a digital signal processor, which filtered and down sampled the LFPA data stream to a manageable $135 \mathrm{Mb} / \mathrm{sec}$. A single frame from the 512 x 512 pixel visible/NIR camera for each IR scan was added to the data stream by the command and data handling system. 


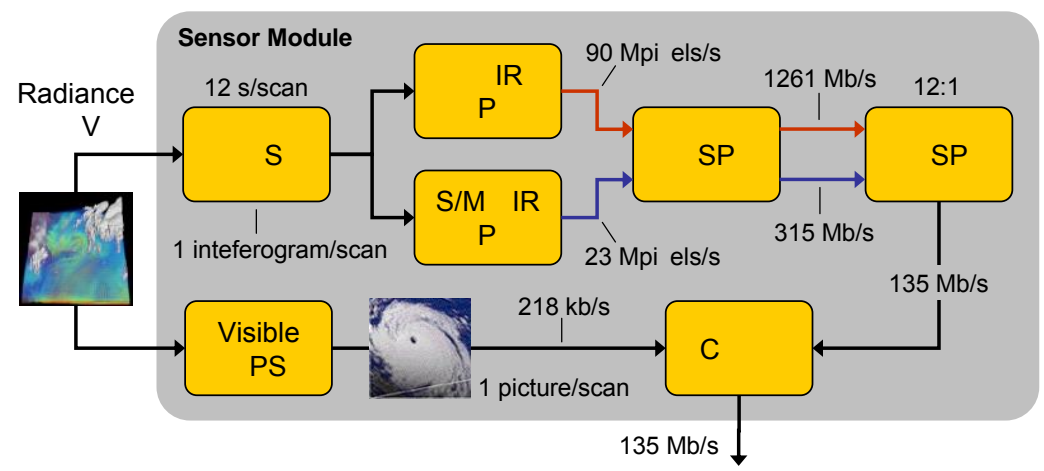

Figure 5. A schematic diagram of the GIFTS data collection and processing system.

\subsection{Performance testing and demonstration}

While all of the GIFTS major components were ordered as flight hardware, near the middle of the assembly it was discovered that the Navy had eliminated funding for the spacecraft and in quick succession, the Air Force canceled the launch vehicle. NASA was left with the choice to finish the unit as a non-flight Engineering Demonstration Unit (EDU) or to cancel it outright. GIFTS was completed as an EDU, completed a full thermal vacuum calibration cycle, and some significant external atmosphere measurements. The GIFTS EDU met all of its radiometric performance requirements.

NASA also funded a series of external measurements to demonstrate the maturity of their newly developed technologies. A large ZnSe window was installed on the GIFTS thermal vacuum chamber that allowed the sensor aperture to view a roll up door in the calibration laboratory (see Figure 6).

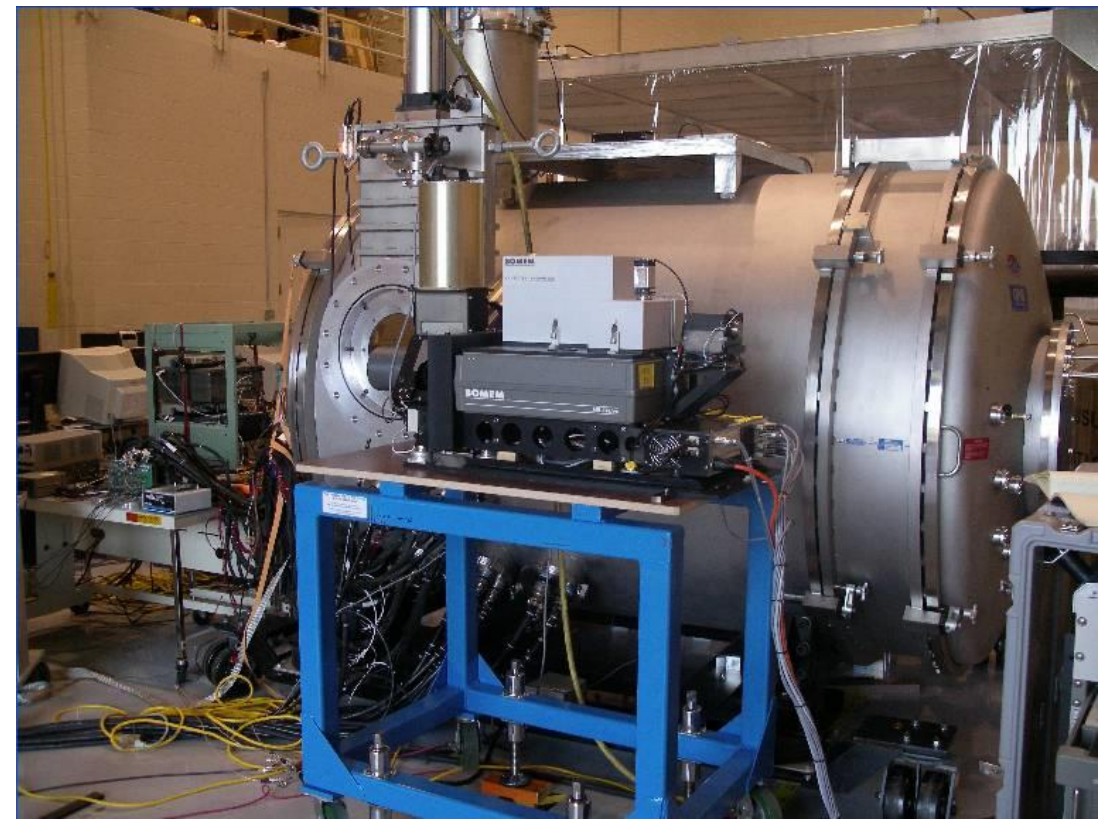

Figure 6. The GIFTS thermal vacuum chamber with the window to allow viewing the outside environment. The UW AERI is located on the table near the chamber to provide a comparison reference measurement for the GIFTS data. Both system viewed a large turning mirror outside the build to make vertical and horizontal scene measurements.

Three sets of external measurements were made: a moon tracking experiment, a six hour series of uplooking atmospheric soundings, and a horizontal mountain scene measurement ${ }^{8}$. The Atmospheric Emitted Radiance Interferometer ${ }^{9}$ (AERI) instrument was designed and fabricated by the University of Wisconsin Space Science and Engineering Center (UW-SSEC) for the Department of Energy (DOE) Atmospheric Radiation Measurement (ARM) Program as an up-looking radiance reference. Spectra collected by the 
individual GIFTS pixels and AERI instrument were identical ${ }^{10}$ to within the instrument noise level (see Figure 7).

The imaging capability of the GIFTS EDU was demonstrated by capturing images and spectra from the passing moon. Figure 8 shows images from the 3 GIFTS LFPAs, the LW on the left, the visible in the middle, and the S/MW on the right. The IR images are from a single wavenumber bin in an atmospheric window region. Spectra for each of the IR pass bands are shown below the moon images, with arrows pointing to the region pixel from which the spectra were developed.

(a) Accurate radiances obtained from GIFTS EDU

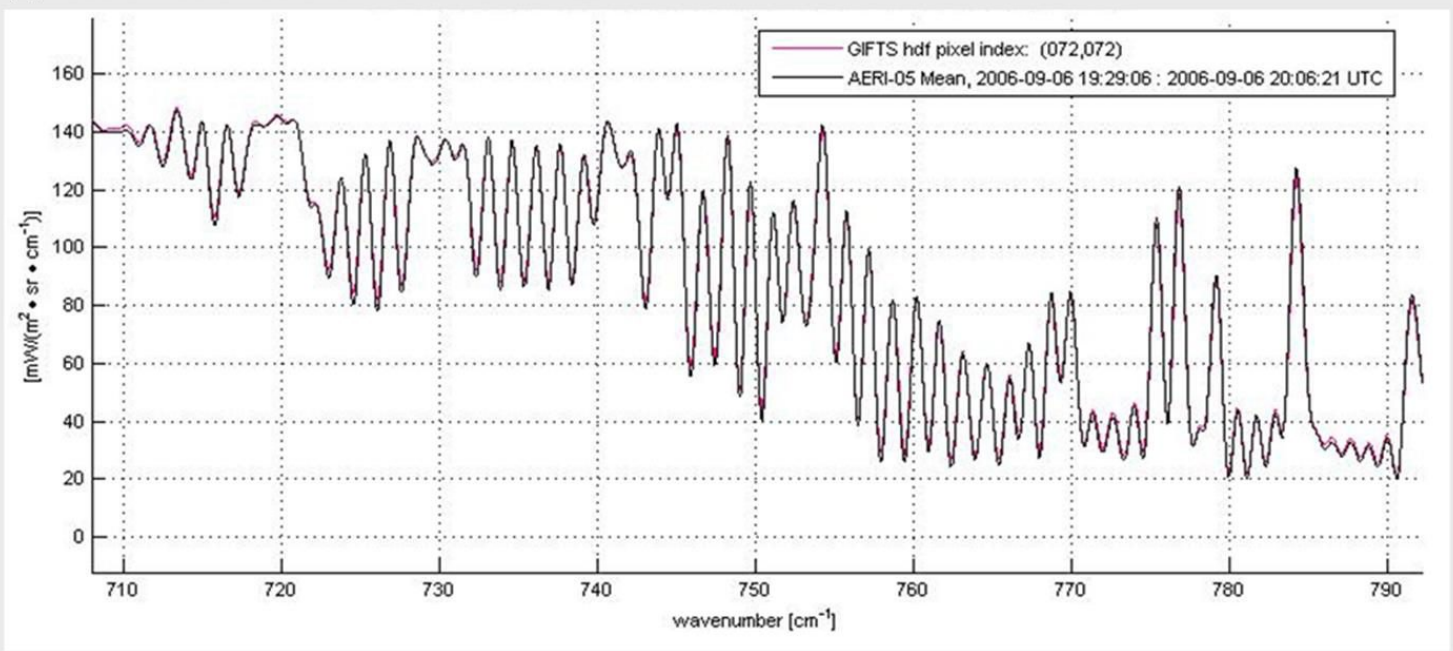

Figure 7. Atmospheric radiance spectra made by GIFTS (pixel 072,072) and the AERI 5.

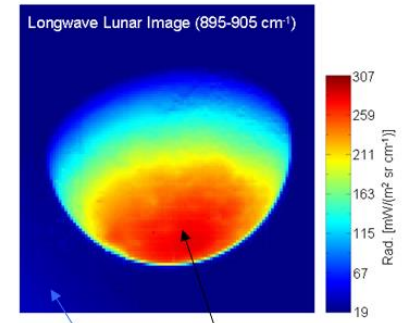

Radiance for pixel of Moon (red) and Sky (blue)

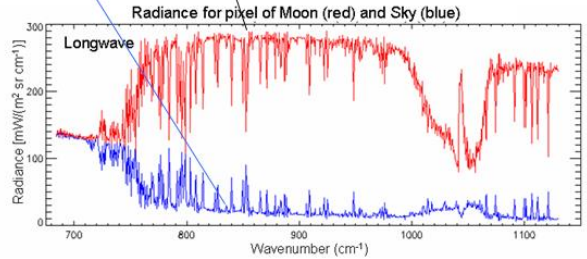

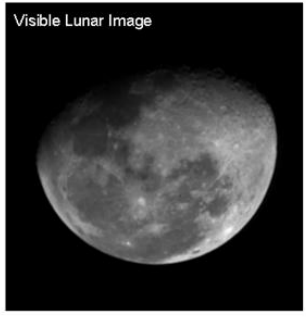

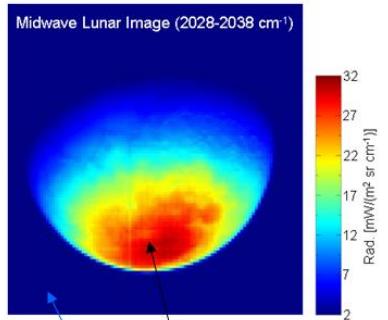

Radiance for pixel of Moon (red) and Sky (blue)

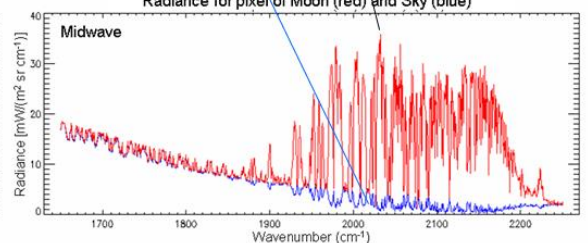

Figure 8. Images of the moon captured by a single interferometer scan of the GIFTS EDU, with single pixel spectra from the moon surface and the deep space around the moon. Note the atmospheric structure in the space view.

After the test program was completed, the GIFTS EDU was mothballed and stored at SDL until 2012, when it was shipped to the NASA Langley Research Center for continued storage.

\subsection{Another start, another stop}

Having successfully matured the selected EO3 technologies, GIFTS was provided to NOAA as the base technology for the Hyperspectral Environmental Suite (HES) for the GOES R procurement. After several options were explored, requirements expanded, and three Phase A studies completed, the HES option was dropped for financial reasons. A major contributor to the decision was the cost of the certified ground processing system to handle the flood of data that HES would have provided. 


\section{REVIVING GIFTS TECHNOLOGY}

The GIFTS team spent the next several years looking around the world for government support to complete and launch the GIFTS ultra-spectral sounder and demonstrate its tremendous value in saving lives and property. It eventually became obvious that a new approach was required to realize this goal.

\subsection{The commercial funding model}

A startup company was formed to secure commercial funding for instrument development, with the concept to eliminate the launch cost by entering a revenue sharing agreement with a commercial communications satellite operator. GeoMetWatch (GMW), was founded in 2008 and is registered in Nevada. On September 15, 2010, GMW was granted the first commercial remote sensing license from the US Department of Commerce to receive and sell atmospheric data collected from geosynchronous orbit. GMW formed a strategic partnership with Utah State University (USU) in 2010 to upgrade the GIFTS design to become their sensor solution. In 2011, GMW began working earnestly with satellite service providers and satellite bus providers throughout the world to establish a presence and to look for a hosting partner. In 2013 this effort had a successful conclusion when the Asia Satellite Telecommunications Company Limited (AsiaSat) and GMW Corp announced that the two companies had entered into a strategic partnership to host the first of six Sounding and Tracking Observatory for Regional Meteorology (STORM $\left.\mathrm{TM}_{\mathrm{TM}}\right)$ instruments on board a new satellite planned to be launched by AsiaSat in 2016. The latest step in this ongoing effort occurred recently, when NASA and GMW signed a Space Act Agreement to return the GIFTS sensor to Utah to provide a testbed for the new $\mathrm{STORM}_{\mathrm{TM}}$ components.

\subsection{Formation of the Advanced Weather Systems foundation}

GIFTS was developed by the Utah State University Research Foundation's Space Dynamics Laboratory (SDL), which is also a US Department of Defense University Affiliated Research Center. To avoid conflict with that role, USU established a new foundation, the Advanced Weather Systems Foundation (AWS) to handle commercial contracts, including the GMW STORM $\mathrm{TM}_{\mathrm{TM}}$ program. AWS is a wholly owned and controlled, not-for-profit foundation under USU. Several of the key SDL GIFTS team members transferred to AWS to push the STORM $\mathrm{TM}_{\mathrm{TM}}$ program forward. As a strategic partner of GMW, AWS is currently participating with the other GMW partners to bring the $\mathrm{STORM}_{\mathrm{TM}}$ sensor to reality.

\subsection{STORM $_{\text {TM }}$ from GIFTS}

While GMW presentations often present the "capability" that can be provided by a STORM $\mathrm{TM}_{\mathrm{TM}}$ sensor, the first instrument (STORM $\left.\mathrm{TM}^{-1}\right)$ is proposed as having the same capability as the original GIFTS sensor, wherever possible. The purpose of this limitation is to minimize risk and shorten development time to a minimum. Because of challenges in finalizing total program funding, making a late 2016 launch date will be a challenge, despite the team having built this sensor before. The primary schedule drivers in $\mathrm{STORM}_{\mathrm{TM}^{-}}$- fabrication are the long lead items and the redesign of the electronics using modern electronic parts.

The specifications for $\mathrm{STORM}_{\mathrm{TM}}{ }^{-1}$, as compared to GIFTS are shown in Table 1. The band pass regions AWS has proposed to GMW are the same, to eliminate the need to design new filters and optics. Spectral resolution options have been reduced from 7 to 3 to reduce testing \& calibration time. Lower resolutions can be achieved by truncating the interferogram, but collecting a shorter interferogram does not save sample time as the limit becomes the time required to collect and save the visible image during each scan. System FOV and FOR remain the same, providing $4 \mathrm{Km}$ footprints and a $512 \mathrm{Km}$ image with the IR cameras. The NESR specifications have not changed, but were exceeded by GIFTS and are expected to be better for STORM $\mathrm{TM}_{\mathrm{TM}}$. Data rates are the same as GIFTS, but the mass has increased to allow for extra solar shielding as $\mathrm{STORM}_{\mathrm{TM}}{ }^{-1}$ will not be able to use a yaw flip on the communications satellite. In addition, STORM $_{\mathrm{TM}^{-}}-1$ will be fully redundant, a change from the GIFTS single string design. This is required to allow the sensor to meet the 15 -year lifetime of the host satellite. The lack of a yaw flip also increases the power requirement for the cyro-cooler during the Austral summer. 
Table 1. Specification comparison between the GIFTS EDU and STORM $\mathrm{TM}^{-1}$.

\begin{tabular}{|l|l|l|}
\hline \multicolumn{1}{|c|}{ Parameter } & \multicolumn{1}{c|}{ GIFTS } & \multicolumn{1}{c|}{ STORM $_{\text {TM }}$} \\
\hline Spectral bands & $\begin{array}{l}\text { LW: } \leq 685 \mathrm{~cm}^{-1} \text { to } \geq 1130 \mathrm{~cm}^{-1} \\
\text { SMW: } \leq 1650 \mathrm{~cm}^{-1} \text { to } \geq 2250 \mathrm{~cm}^{-1} \\
\text { VIS: } \geq 0.725 \mu \mathrm{m} \text { to } \leq 0.875 \mu \mathrm{m}\end{array}$ & same \\
\hline Spectral resolution & 7 resolutions in range $0.6-36.7 \mathrm{~cm}^{-1}$ & $0.6,1.2$, and $9.6 \mathrm{~cm}^{-1}$ \\
\hline FPA field-of-view (FOV) & $14.3 \mathrm{mrad}\left(0.82^{\circ}\right)$ & same \\
\hline Field-of-regard (FOR) & $\begin{array}{l}\geq 0.306 \mathrm{rad}\left(17.53^{\circ}\right) \\
\text { (pointing mirror design: } 0.450 \mathrm{rad})\end{array}$ & same \\
\hline IR FPA format & $128 \mathrm{X} 128$ pixels, $60 \mu \mathrm{m} \mathrm{pixel} \mathrm{pitch}^{-1}$ & same \\
\hline $\begin{array}{l}\text { Noise equivalent spectral } \\
\text { radiance (NESR) goal }\end{array}$ & $\begin{array}{l}\text { LW: } \leq 0.4 \mathrm{~mW} /\left(\mathrm{m}^{2}-\mathrm{sr}-\mathrm{cm}^{-1}\right) \\
\text { SMW: } \leq 0.06 \mathrm{~mW} /\left(\mathrm{m}^{2}-\mathrm{sr}_{-1} \mathrm{~cm}^{-1}\right)\end{array}$ & same \\
\hline Calibration accuracy goal & $\leq 1 \mathrm{~K}(3 \sigma)$ & same \\
\hline Data rate & $\begin{array}{l}\text { Max: } 70-80 \mathrm{Mb} / \mathrm{sec} \\
\text { Nom: } 58-73 \mathrm{Mb} / \mathrm{sec}\end{array}$ & same \\
\hline
\end{tabular}

While mass was an important issue on the GIFTS-IOMI satellite, the communications satellites being considered for the AsiaSat 9 mission are so large that mass is not an issue for $\mathrm{STORM}_{\mathrm{TM}}-1$. Nor is the heat rejection capability requirement because of the large surfaces of the expected bus. However, designing a precision spectral radiometric sensor to provide stable, accurate measurements for a 15 -year lifetime is a challenge not specified for any of the government remote sensing instruments. This aspect of the STORM $_{\mathrm{TM}}$ design is being carefully studied.

\section{SUMMARY}

A new approach to weather data collection and delivery has been initiated by GMW in an attempt to secure ultra-spectral weather and atmospheric state data from GEO orbit. GMW's three strategic partners, the Advanced Weather Systems foundation at Utah State University, the Space Science and Engineering Center at the University of Wisconsin - Madison, and the Asia Satellite Telecommunications Company Limited are committed to bring this valuable data to government and commercial customers under AsiaSat 9 at $122 \mathrm{E}$ in late 2016. The GIFTS team, including our NASA sponsor are anxious to see this next advance in earth observation come to fruition after more than a decade of effort. If GMW is successful in developing its full constellation of six regularly spaced GEO satellites, it will provide data of unprecedented value to people around the world living in the latitude band from 60 degrees north and south of the equator, protecting the lives of more than $70 \%$ of the world's population.

\section{REFERENCES}

[1.] GeoMetWatch, Inc.770 North Research Park Way, North Logan, UT 84341. http:/geometwatch.com/

[2.] NOAA Administrator Conrad Lautenbacher stated in an August 24, 2005 press release: "The AIRS instrument has provided the most significant increase in forecast improvement in this time range of any other single instrument".

[3.] Smith, W. L., Woolf, H. M., Hayden, C. M., Wark, D. Q., and McMillin, L. M.: The TIROS-N operational vertical sounder, B.Am. Meteor. Soc., 60, 1177-1187, 1979.

[4.] Smith, W. L., Suomi, V. E., Menzel, W. P., Woolf, H. M., Sromovsky, L. A., Revercomb, H. E., Hayden, C. M., Erickson, D. N., and Mosher, F. R.: First sounding results from VAS-D, B. Am. Meteor. Soc., 62, 232236, 1981.

[5.] Smith, W. L., Revercomb, H. E., Howell, H. B., Woolf, H. M., and LaPorte, D. D.: The High Resolution Interferometer Sounder (HIS). In: Atmospheric Radiation Progress and Prospects: Beijing International Radiation Symposium, Beijing, China, 26-30 August 1986, Boston, MA, American Meteorological Society, 1987, 271-281, 1986.

[6.] Smith, W. L., Zhou, D. K., Larar, A. M., Mango, S. A., Knuteson, H. B., Revercomb, H. E., and Smith Jr., W. L.: The NPOESS Airborne Testbed Interferometer - Remotely Sensed Surface and Atmospheric Conditions during CLAMS, J. Atmos. Sci., 62, 1118-1134, 2005. 
[7.] Smith, W. L., Harrison, F. W., Revercomb, H. E., and Bingham, G. E.: Geostationary Fourier Transform Spectrometer (GIFTS) - The New Millennium Earth Observing-3 Mission. IRS 2000: Current problems in atmospheric radiation. Proceedings of the International Radiation Symposium, St. Petersburg, Russia, 24-29 July 2000. Hampton, VA, A. Deepak Publishing, 81-84, 2001.

[8.] Zhou, D. K., Smith Sr., W. L., Bingham, G. E., Huppi, R. J., Revercomb, H. E., Zollinger, L. J., Elwell, J. D., Larar, A. M., Liu, X., Tansock, J. J., Reisse, R. A., and Hooker, R.: Ground-based measurements with the Geosynchronous Imaging Fourier Transform Spectrometer (GIFTS) engineering demonstration unit experiment description and first results, J. Appl. Remote Sens., 1, 013528, doi:10.1117/1.2784288, 2007.

[9.] Knuteson, R. O., H. E. Revercomb, F. A. Best, N. C. Ciganovich, R. G. Dedecker, T. P. Dirkx, S. C. Ellington, W. F. Feltz, R. K. Garcia, H. B. Howell, W. L. Smith, J. F. Short, and D. C. Tobin. Atmospheric Emitted Radiance Interferometer. Part I: Instrument Design. J. Atmos. Oceanic Technol., 21, 1763-1776.

[10.]Smith Sr, W. L. H. Revercomb, G. Bingham, A. Larar, H. Huang, D. Zhou, J. Li, X. Liu, and S. Kireev. Technical Note: Evolution, current capabilities, and future advance in satellite nadir viewing ultra-spectral IR sounding of the lower atmosphere. Atmos. Chem. Phys., 9, 5563-5574, 2009. 